\title{
Morphometrics as a predictor of perioperative morbidity after lumbar spine surgery
}

\author{
Hesham Mostafa Zakaria, MD, ${ }^{1}$ Lonni Schultz, PhD, ${ }^{2}$ Feras Mossa-Basha, MD, ${ }^{3}$ Brent Griffith, MD, ${ }^{3}$ \\ and Victor Chang, MD'
}

Departments of ${ }^{1}$ Neurosurgery, ${ }^{2}$ Public Health Sciences, and ${ }^{3}$ Radiology, Neuroscience Institute, Henry Ford Health System, Detroit, Michigan

OBJECT Improved objective assessments of perioperative risk after spine surgery are necessary to decrease postoperative morbidity and mortality rates. Morphometric analysis has proven utility in predicting postoperative morbidity and mortality in surgical disciplines. The aim of the present study was to evaluate whether morphometrics can be applied to the cases of patients undergoing lumbar spine surgery.

METHODS The authors performed a retrospective review of the perioperative course of 395 patients who underwent lumbar surgery at their institution from 2013 to 2014. Preoperative risk factors such as age, diabetes, smoking, coronary artery disease, and body mass index (BMI) were recorded. Preoperative MRI was used to measure the psoas muscle area at the L-4 vertebra and paraspinal muscle area at the T-12 vertebra. Primary outcomes included unplanned return to the operating room, 30- and 90-day readmissions, surgical site infection, wound dehiscence, new neurological deficit, deep vein thrombosis, pulmonary embolism, myocardial infarction, urinary tract infection, urinary retention, hospitalacquired pneumonia, stroke, and prolonged stay in the intensive care unit.

RESULTS The overall rate of adverse events was 30\%, the most common event being urinary retention (12\%). Greater age $(p=0.015)$ and tobacco usage $(p=0.026)$ were both significantly associated with complications for all patients, while diabetes, coronary artery disease, and high BMI were not. No surgery-related characteristics were associated with postoperative morbidity, including whether surgery required instrumentation, whether it was a revision, or the number of vertebral levels treated. Using multivariate regression analysis, male and female patients with the lowest psoas tertile had an OR of $1.70(95 \% \mathrm{Cl} 1.04-2.79, p=0.035)$ for having postoperative complications. Male patients in the lowest psoas tertile had an OR of $2.42(95 \% \mathrm{Cl} 1.17-5.01, p=0.016)$ for having a postoperative complication. The paraspinal muscle groups did not provide any significant data for postoperative morbidity, even after multivariate analysis.

CONCLUSIONS The morphometric measurement of psoas muscle size may be a sensitive predictive tool compared with other risk factors for perioperative morbidity in male patients undergoing lumbar surgery.

http://thejns.org/doi/abs/10.3171/2015.7.FOCUS15257

KEY WORDS morphometrics; lumbar spine complications; frailty index

\section{$\mathrm{L}$}

OW-BACK pain is a common disorder, contributing to a large portion of health care costs. ${ }^{15,20}$ Over the past decade, there has been a noticeable increase in the frequency of elective lumbar surgery (decompressions and arthrodesis), ${ }^{19,28,35}$ perhaps due its proven effectiveness. ${ }^{32-34}$ However, this is associated with an increase in the frequency of postoperative complications after spinal surgery. ${ }^{3,11,25}$ With the current focus on cost-efficient health care, it is important to identify patients who are at greater risk for postoperative morbidity and mortality, which may require greater resource utilization. ${ }^{3,11}$

A patient's general health status is an important consideration when weighing which surgical approaches are appropriate for a given pathology, always with the aim of minimizing the potential perioperative morbidity. However, the factors that contribute to a surgeon's decision regarding patient selection and surgical approach are generally empirical and without the benefit of a validated

ABBREVIATIONS BMI = body mass index; CAD = coronary artery disease; DVT = deep vein thrombosis; HFHS = Henry Ford Health System; ICC = intraclass correlation coefficient; LOS = length of stay; MI = myocardial infarction; $\mathrm{PE}=$ pulmonary embolism; UTI = urinary tract infection.

SUBMITTED May 26, 2015. ACCEPTED July 10, 2015.

INCLUDE WHEN CITING DOI: 10.3171/2015.7.FOCUS15257. 
risk assessment tool. Factors such as age, smoking status, obesity, coronary artery disease (CAD), chronic obstructive pulmonary disease, diabetes, severity of symptoms, and complexity of the surgery are all important, but their relative contribution to overall perioperative risk is not well quantified. Validated risk-stratification tools provide objective data to surgeons to one aspect of a patient's operative risk (cardiovascular, pulmonary, psychological, etc.), $)^{8,10,16,23,26,29,30}$ but their utility to spinal surgery is limited. Given that the vast majority of spinal procedures are elective, surgical candidates are generally without any active exacerbations of their medical problems. Despite diligent patient selection and preoperative screening and optimization, elective spinal procedures are still potentially associated with morbidity. ${ }^{27}$ Ultimately, risk calculations may be insufficient to assess the overall health of a patient, as two patients with the same preoperative risk factors (i.e., age, American Society of Anesthesiologists score, comorbidities, and disease stage) are often in clearly different stages of health. Surgeons will often "eyeball" patients to see if they are fit for surgery, and surgeons make operative decisions regardless of risk stratification.

Recently, the concept of frailty has been introduced as a measure of a patient's health status. ${ }^{9,21}$ Frailty is defined as "a biologic syndrome of decreased reserve and resistance to stressors, resulting from cumulative declines across multiple physiologic systems." ${ }^{, 21}$ While it is a common end point to human senescence, this process is pathological and has been shown to be associated with adverse outcomes after surgery. ${ }^{1,5,14}$ Unfortunately, measuring human frailty relies on subjective assessments and prolonged patient cooperation, which is impractical in application. ${ }^{1,14}$ Surrogate markers of frailty, such as sarcopenia, may be more useful to clinicians. Morphometrics is the measurement of patient attributes that are indicative of sarcopenia and thus frailty by proxy. Morphometric analysis has proven utility in predicting postoperative morbidity and mortality following major general, vascular, and transplant surgery. $2,4,6,7,12,13,17,18,22,24,31$ This study evaluates whether morphometrics can be used as a reliable predictor of perioperative morbidity in patients undergoing lumbar spine surgery.

\section{Methods \\ Chart Review}

This is a retrospective cohort study of patients undergoing lumbar surgery within the Henry Ford Health System (HFHS). After obtaining institutional review board approval, we compiled a list of all patients who had undergone lumbar surgery (T-11 through S-1, inclusive) at HFHS from 2013 to 2014. We used the Current Procedural Terminology (CPT) codes for lumbar laminectomy, lumbar posterior/posterolateral arthrodesis, and lumbar interbody arthrodesis and identified 466 patients. Using the electronic medical records, each patient's preoperative risk factors, including age, sex, and status pertaining to diabetes, smoking, CAD, and body mass index (BMI), were entered into the database. Variables pertaining to operative details as well as immediate postoperative stay included the number of vertebral levels treated, whether the surgery was a revision, whether there was instrumentation, the length of stay (LOS), and disposition at discharge (home, skilled nursing facility, acute rehabilitation facility). Primary outcomes recorded included any 90 -day postoperative complications including: death, unplanned return to surgery, 30- and 90-day hospital readmission, surgical site infection, wound dehiscence, new neurological deficit, deep vein thrombosis (DVT), pulmonary embolism (PE), myocardial infarction (MI), urinary tract infection (UTI), urinary retention, hospital-acquired pneumonia, stroke, and prolonged stay ( $>3$ days) in the intensive care unit.

\section{Analytical Morphometrics}

Our analytical morphometrics methodology has been adopted from that described by Englesbe et al. ${ }^{2,31}$ and applied to preoperative MRI. Using the freehand region of interest tool on Philips ePACS viewer, the circumferential area of each patient's psoas muscles at L-4 and paraspinal muscles at T-12 were measured on axial T2-weighted MRI sequences (Fig. 1). Muscle area was calculated in cubic centimeters, and the areas for each muscle were entered in our database. For a reliability assessment of the freehand identification of the region of interest, a random sample of 40 patients (20 males and 20 females) was selected and measured by 3 observers (H.Z., B.G., and V.C.) independently.

\section{Statistical Analysis}

To assess differences in demographic and surgical information and morphometric measurements associated with complications, chi-square tests were performed for categorical/binary variables and 2-sample t-tests for the continuous variables. A Wilcoxon 2-sample nonparametric test was used to compare patients with and without complications for number of vertebral levels treated. Due to sex differences in the morphometric measurements, cut-points for the tertiles were determined separately for males and females. Chi-square and Kruskal-Wallis tests were performed to assess the association between the tertile measurements and specific complications and total number of complications. Multivariate logistic regression was done to adjust for potential confounders when assessing the relationship between experiencing any complication and psoas tertiles. Kruskal-Wallis tests were used to assess the association of LOS with total psoas and total paraspinous tertiles. The associations of discharge disposition and tertiles for total psoas and paraspinous muscles were investigated using chi-square tests. Sex differences in the morphometric measurements were tested using 2 -sample t-tests. Intraclass correlation coefficients (ICCs) were computed to assess the reliability among observers of the morphometric measurements of the right and left psoas and paraspinous muscles, as well as the total psoas and paraspinous muscles. All testing was done at the 0.05 level. SAS version 9.4 was used for data analysis.

\section{Results \\ Participants}

A total of 466 patients were identified and their data entered in the database. Of the 466 patients, 8 were excluded 


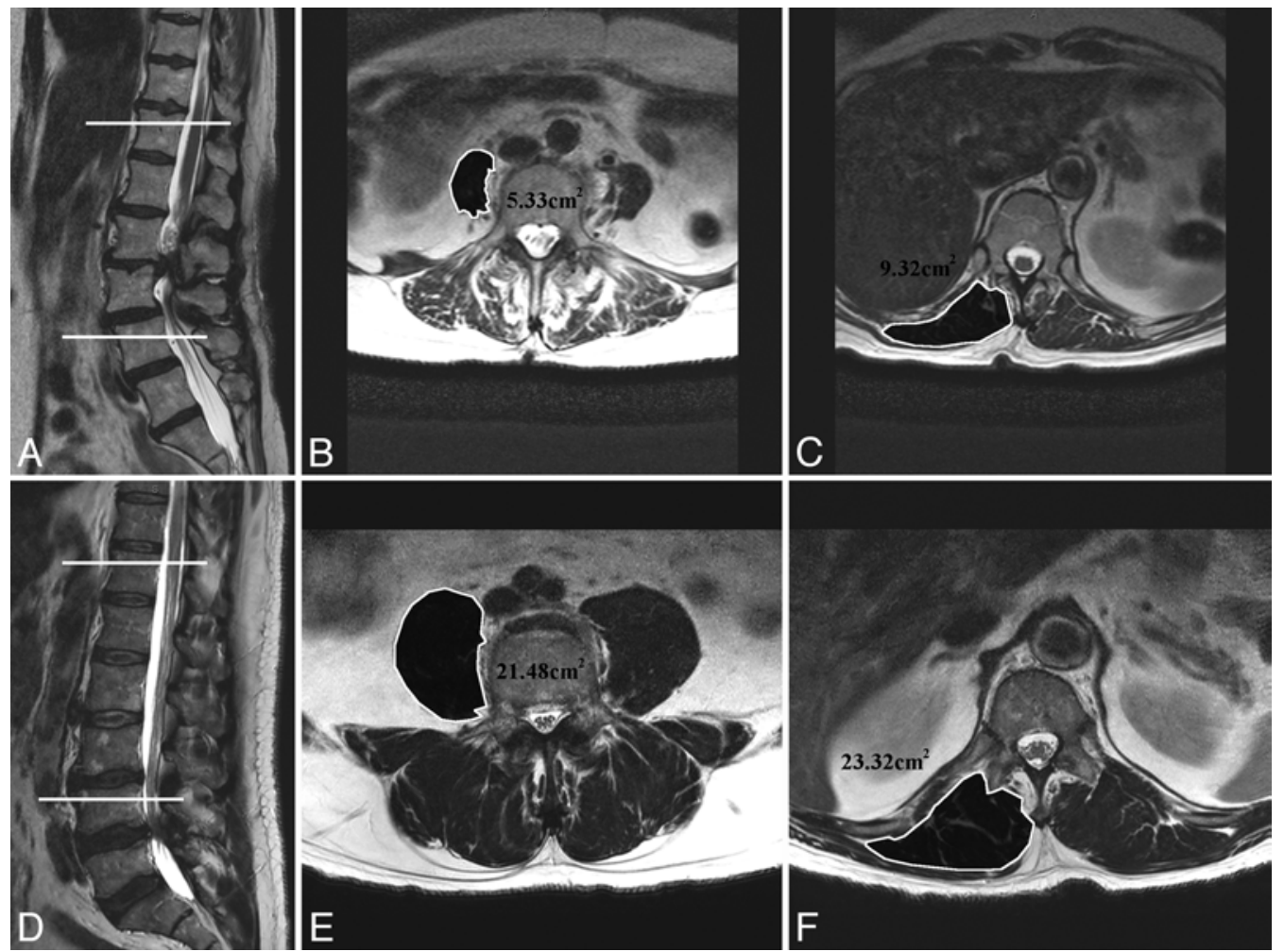

FIG. 1. Examples of morphometric measurements on T2-weighted MR images obtained in patient with $(A-C)$ and without (D-F) sarcopenia. A: Sagittal image of a patient with sarcopenia. The white lines through the L-4 and T-12 vertebrae are example crosssections from which morphometric measurements were taken. B: Axial image, of the same patient, taken at the L-4 vertebra showing a small psoas muscle measuring $5.33 \mathrm{~cm}^{2}$. C: Axial image, of the same patient, obtained at the T-12 vertebra showing a small paraspinal muscle measuring $9.32 \mathrm{~cm}^{2}$. D: Sagittal image of a patient without sarcopenia. The white lines through the L-4 and T-12 vertebrae again show example cross-sections from which morphometric measurements were taken. E: Axial image, of the patient, demonstrating a large psoas muscle measuring $21.48 \mathrm{~cm}^{2}$. F: Axial image, of the same patient, demonstrating a large paraspinal muscle measuring $23.32 \mathrm{~cm}^{2}$.

due to duplicate records, 19 were excluded due to having undergone nonlumbar surgery, and 30 were excluded due to inadequate imaging (i.e., MR images not available or incorrectly formatted for morphometric analysis). Of the remaining 409 patients, 14 were excluded due to incomplete medical records, leaving 395 patients for statistical analysis. Three patients had two elective surgeries recorded, but only the first one was used in the analysis.

\section{Descriptive Data}

A summary of descriptive information can be found in Table 1. The mean age of all patients was 63.3 years (SD \pm 12.48 , median 63 , range $23-88$ ). Of the 395 patients, $51 \%(\mathrm{n}=203)$ were female, $24 \%(\mathrm{n}=94)$ had diabetes, $27 \%(\mathrm{n}=105)$ were smokers, $16 \%(\mathrm{n}=62)$ had CAD, and mean BMI was 30.92 ( $\mathrm{SD} \pm 6.44$, median 30, range 16.45 to 55.51$)$. Of the 395 surgeries, $54 \%(\mathrm{n}=213)$ were instrumentations and 29\% $(\mathrm{n}=113)$ were revisions. Regarding complexity, $30 \%(n=119)$ were 1-level procedures, of which $43 \%$ were instrumented and $25 \%$ were revisions; $31 \%(\mathrm{n}=122)$ were 2 -level procedures, of which $58 \%$ were instrumented and 28\% were revisions; the remaining $39 \%$ $(n=154)$ were multilevel operations, of which $60 \%$ were instrumented and 34\% were revisions. Only 14 cases were minimally invasive surgeries (MIS), complementing $4 \%$ of our patient population.

\section{Outcome Data}

Table 2 contains the types of the complications and their respective rates, as well as LOS and discharge disposition. Of the 395 patients who had surgery, $30 \%$ ( $\mathrm{n}=$ 120) had at least one complication, with the most common complication being urinary retention $(12 \%, \mathrm{n}=46)$, followed by surgical site infection $(9 \%, \mathrm{n}=36)$ and unplanned readmission within 90 days $(9 \%, \mathrm{n}=36$ ) (Table 2). The mean LOS was 3.89 days $(\mathrm{SD} \pm 2.97$, median 3 , range $0-27$ days), with $71 \%(n=278)$ of patients being discharged home immediately thereafter (Table 2).

\section{Postoperative Complication Analysis}

Table 3 contains the comparisons for patients with and without complications. The differences between the groups were significant for age (patients who had complications were an average of 3 years older [65.6 vs 62.3 years, $\mathrm{p}=0.015]$ ) and smoking (patients who had complications were less likely to be smoking $[19 \%$ vs $30 \%$, p $=0.026])$. Female sex approached significance in terms of having more complications than males $(\mathrm{p}=0.068)$. No significant association was found for diabetes, CAD, BMI, number of vertebral levels treated, and whether surgery involved instrumentation or was a revision. These same comparisons of patients with and without complications were performed for females and males due to the observed 
TABLE 1. Summary of descriptive features*

\begin{tabular}{|c|c|}
\hline Variable & All Patients $(n=395)$ \\
\hline \multicolumn{2}{|l|}{ Demographics } \\
\hline \multicolumn{2}{|l|}{ Age (yrs) } \\
\hline Mean \pm SD & $63.30 \pm 12.48$ \\
\hline Median (range) & $64(23-80)$ \\
\hline \multicolumn{2}{|l|}{ Sex } \\
\hline Female & $203(51 \%)$ \\
\hline Male & $192(49 \%)$ \\
\hline \multicolumn{2}{|l|}{ Risk factors } \\
\hline Diabetes & $94(24 \%)$ \\
\hline Smoking & $105(27 \%)$ \\
\hline CAD & $62(16 \%)$ \\
\hline \multicolumn{2}{|l|}{ BMI } \\
\hline \multicolumn{2}{|l|}{ Mean \pm SD } \\
\hline Median (range) & $30.92 \pm 6.4430$ (16.45 to 55.51$)$ \\
\hline \multicolumn{2}{|l|}{ Surgical information } \\
\hline Instrumented & $213(54 \%)$ \\
\hline Revision & $113(29 \%)$ \\
\hline MIS & $14(4 \%)$ \\
\hline \multicolumn{2}{|l|}{ No. of levels treated } \\
\hline 1 & $119(30 \%)$ \\
\hline 2 & $122(31 \%)$ \\
\hline 3 & $77(19 \%)$ \\
\hline 4 & $48(12 \%)$ \\
\hline 5 & $21(5 \%)$ \\
\hline 6 & $3(1 \%)$ \\
\hline 7 & $3(1 \%)$ \\
\hline 8 & $1(0 \%)$ \\
\hline 10 & $1(0 \%)$ \\
\hline \multicolumn{2}{|l|}{ Mean \pm SD } \\
\hline Median (range) & $2.40 \pm 1.372(0$ to 10$)$ \\
\hline
\end{tabular}

MIS = minimally invasive surgery.

* Values are presented as the mean $\pm \mathrm{SD}$, median (range), or number (\%).

sex differences. For females, the only significant difference observed was that patients with complications had a higher mean BMI than patients without complications ( $\mathrm{p}$ $=0.021)$, while age $(p=0.098)$ and smoking $(p=0.064)$ trended toward significance. For males, trends were also seen for age (males with complications on average were older $[p=0.076])$ and CAD (30\% patients with complications had CAD, whereas $18 \%$ those without complications had CAD [ $p=0.063])$. No significant differences in complication rates were seen when comparing cases of minimally invasive surgery and open surgery (Table 3 ).

\section{Morphometric Results}

The ICCs for the psoas muscles were extremely high or almost perfect with a range from 0.988 to 0.991 , indicating that the 3 independent observers were able to each precisely measure psoas muscle sizes. For the paraspinous muscles, the ICCs were lower than the psoas, but were still very good with a range from 0.842 to 0.857 . Table
TABLE 2. Outcomes and complications

\begin{tabular}{|c|c|}
\hline Variable & All Patients $(n=395)$ \\
\hline \multicolumn{2}{|l|}{ Complications } \\
\hline Mortality & $1(0 \%)$ \\
\hline Unplanned return to OR & $20(5 \%)$ \\
\hline Unplanned readmission 30 days & $30(8 \%)$ \\
\hline Unplanned readmission 90 days & $36(9 \%)$ \\
\hline Surgical site infection & $36(9 \%)$ \\
\hline Wound dehiscence & $24(6 \%)$ \\
\hline New neurological deficit & $7(2 \%)$ \\
\hline DVT & $12(3 \%)$ \\
\hline PE & $6(2 \%)$ \\
\hline Ml & $4(1 \%)$ \\
\hline UTI & $18(5 \%)$ \\
\hline Urinary retention & $46(12 \%)$ \\
\hline Pneumonia & $9(2 \%)$ \\
\hline Prolonged ICU stay $>3$ days & $7(2 \%)$ \\
\hline CVA & $1(0 \%)$ \\
\hline Any complication & $120(30 \%)$ \\
\hline \multicolumn{2}{|l|}{ Other outcomes } \\
\hline \multicolumn{2}{|l|}{ LOS, days } \\
\hline Mean + SD & $3.89 \pm 2.97$ \\
\hline Median (range) & $3(0-27)$ \\
\hline \multicolumn{2}{|l|}{ Disposition } \\
\hline Home & $278(71 \%)$ \\
\hline Acute rehab & $38(10 \%)$ \\
\hline Skilled nursing facility & $78(20 \%)$ \\
\hline
\end{tabular}

$\mathrm{CVA}=$ cerebrovascular accident; $\mathrm{ICU}=$ intensive care unit; $\mathrm{OR}=$ operating room.

4 contains descriptive information for the morphometric measurements for all patients. For each morphometric location, the average area and total muscle area (psoas or paraspinous) were used. Average here refers to the mean between the right and left muscle area within a particular individual, and the total refers to the sum of both muscles for each individual. For all measurements, the differences were significant, with males having higher muscle sizes than females when comparing average psoas areas (14.98 \pm 4.24 vs $9.66 \pm 2.57, \mathrm{p}<0.001)$, total psoas areas $(29.96 \pm$ 8.49 vs $19.32 \pm 5.14, \mathrm{p}<0.001)$, average paraspinous areas $(19.01 \pm 6.28$ vs $14.65 \pm 4.56, \mathrm{p}<0.001)$, and total paraspinous areas $(37.96 \pm 12.61$ vs $28.98 \pm 8.41, \mathrm{p}<0.001)$. Paraspinous area measurements were not obtained in all patients due to the heterogeneity of the overall MRI protocols (i.e., many studies were performed outside HFHS and then uploaded to our ePACs system), several of which did not include axial images up to T-12.

We then compared the morphometric psoas and paraspinal muscle measurements of patients who did not have complications with those who did have complications (Table 5). We divided patients into tertiles based on the size of their psoas and paraspinal muscles, with the highest tertile having the largest muscle sizes and the lowest tertiles having the smallest. Cases in the smallest tertile in terms of average and total psoas areas approached sig- 
TABLE 3. Comparison of patients with and without complications*

\begin{tabular}{|c|c|c|c|}
\hline Variable & $\begin{array}{c}\text { No } \\
\text { Complications } \\
(n=275)\end{array}$ & $\begin{array}{l}\text { Complications } \\
\qquad(\mathrm{n}=120)\end{array}$ & $\begin{array}{c}p \\
\text { Value }\end{array}$ \\
\hline \multicolumn{4}{|l|}{ All patients } \\
\hline Mean age (yrs) & $62.29 \pm 12.31$ & $65.61 \pm 12.61$ & 0.015 \\
\hline Sex & & & 0.068 \\
\hline Female & $133(48 \%)$ & $70(58 \%)$ & \\
\hline Male & $142(52 \%)$ & $50(42 \%)$ & \\
\hline Diabetes & $63(23 \%)$ & $31(26 \%)$ & 0.530 \\
\hline Smoking & $82(30 \%)$ & $23(19 \%)$ & 0.026 \\
\hline CAD & $39(14 \%)$ & $23(19 \%)$ & 0.198 \\
\hline Mean BMI & $30.65 \pm 6.16$ & $31.52 \pm 7.02$ & 0.215 \\
\hline Instrumented & $147(53 \%)$ & $66(55 \%)$ & 0.777 \\
\hline Revision & $83(30 \%)$ & $30(25 \%)$ & 0.295 \\
\hline MIS & $12(4 \%)$ & $2(2 \%)$ & 0.182 \\
\hline Mean no. of levels treated & $2.42 \pm 1.36$ & $2.35 \pm 1.41$ & 0.562 \\
\hline \multicolumn{4}{|l|}{ Female patients } \\
\hline Mean age (yrs) & $62.37 \pm 12.65$ & $65.46 \pm 12.42$ & 0.098 \\
\hline Diabetes & $25(19 \%)$ & $18(26 \%)$ & 0.252 \\
\hline Smoking & $34(26 \%)$ & $10(14 \%)$ & 0.064 \\
\hline CAD & $14(11 \%)$ & $8(12 \%)$ & 0.817 \\
\hline Mean BMI & $30.26 \pm 6.53$ & $32.62 \pm 7.59$ & 0.021 \\
\hline Instrumented & $87(65 \%)$ & $44(63 \%)$ & 0.717 \\
\hline Revision & $46(35 \%)$ & $21(30 \%)$ & 0.509 \\
\hline MIS & $5(4 \%)$ & $1(1 \%)$ & 0.351 \\
\hline Mean no. of levels treated & $2.41 \pm 1.29$ & $2.37 \pm 1.52$ & 0.568 \\
\hline \multicolumn{4}{|l|}{ Male patients } \\
\hline Mean age (yrs) & $62.22 \pm 12.02$ & $65.82 \pm 13.01$ & 0.076 \\
\hline Diabetes & $38(27 \%)$ & $13(26 \%)$ & 0.917 \\
\hline Smoking & $48(34 \%)$ & $13(26 \%)$ & 0.295 \\
\hline CAD & $25(18 \%)$ & $15(30 \%)$ & 0.063 \\
\hline Mean BMI & $31.02 \pm 5.78$ & $29.99 \pm 5.87$ & 0.279 \\
\hline Instrumented & $60(42 \%)$ & $22(44 \%)$ & 0.830 \\
\hline Revision & $37(26 \%)$ & $9(18 \%)$ & 0.251 \\
\hline MIS & $7(5 \%)$ & $1(2 \%)$ & 0.372 \\
\hline Mean no. of levels treated & $2.43 \pm 1.42$ & $2.32 \pm 1.24$ & 0.792 \\
\hline
\end{tabular}

* Mean values are presented \pm SD. Boldface indicates statistical significance. nificance in predicting postoperative morbidity $(\mathrm{p}=0.096$ and $\mathrm{p}=0.052$, respectively). Paraspinal muscle tertiles did not show any significant associations with morbidity. Given the significant difference in psoas size between sexes, we analyzed males and females separately. For female patients, there was no observed trend for either psoas muscles or paraspinal muscles. Male patients with smaller average psoas areas and with smaller total psoas areas were significantly more likely to have postoperative morbidity ( $\mathrm{p}=0.014$ for both). For the morphometric tertiles, differences were significant for average psoas area $(\mathrm{p}=$ $0.032)$ and total psoas area $(p=0.008)$, with patients in the lowest tertile having a greater incidence of complications. There was no observed trend for paraspinal muscle area and morbidity for male patients.

\section{Odds Ratio and Multivariate Analysis of Morphometrics}

Multivariate logistic regression was done to adjust for potential confounders when assessing the relationship between the lowest total psoas tertile versus the middle/ highest tertile (Table 6). The association of complications and BMI remained significant for all patients and for female patients after adjusting for age, CAD, and smoking. The difference between the lowest total psoas tertile and the upper two tertiles remained significant; patients in the lowest tertile had an OR of 1.70 that they would experience complications compared with the other two tertiles (95\% CI 1.04-2.79, $\mathrm{p}=0.035$ ). This association was especially prominent in male patients, with an OR of 2.42 $(95 \%$ CI $1.17-5.01, \mathrm{p}=0.016)$ of experiencing a postoperative morbidity.

\section{Discussion \\ Key Results}

The overall rate of adverse events after lumbar spinal surgery is high, with $30 \%$ of patients experiencing some sort of postoperative morbidity. For all patients, the preoperative characteristics of age and tobacco usage were both significantly associated with complications $(\mathrm{p}=0.015$ and $\mathrm{p}=0.026$, respectively), while diabetes, $\mathrm{CAD}$, and $\mathrm{BMI}$ were not. No surgical characteristics were associated with postoperative morbidity, including whether the surgery required instrumentation, whether it was a revision, or the number of levels treated. Important sex differences were observed. Female sex trended toward greater risk for morbidity $(\mathrm{p}=0.068)$, and BMI was associated with increased morbidity in females $(\mathrm{p}=0.021)$.

TABLE 4. Morphometric measurements*

\begin{tabular}{|c|c|c|c|c|}
\hline Measurements & All Patients $(n=395)$ & Female $(n=203)$ & Male $(n=192)$ & p Value \\
\hline Average L-4 psoas area & $12.25 \pm 4.38$ & $9.66 \pm 2.57$ & $14.98 \pm 4.24$ & $<0.001$ \\
\hline Total L-4 psoas area† & $24.48 \pm 8.76$ & $19.32 \pm 5.14$ & $29.96 \pm 8.49$ & $<0.001$ \\
\hline Average T-12 paraspinous areaf & $16.70 \pm 5.85$ & $14.65 \pm 4.56$ & $19.01 \pm 6.28$ & $<0.001$ \\
\hline Total T-12 paraspinous area§ & $33.18 \pm 11.49$ & $28.98 \pm 8.41$ & $37.96 \pm 12.61$ & $<0.001$ \\
\hline
\end{tabular}


TABLE 5. Morphometric comparisons of patients with and without complications

\begin{tabular}{|c|c|c|c|}
\hline Variable \& Response & No Complications & Complications & p Value* \\
\hline All patients & 275 & 120 & \\
\hline Average psoas tertiles & & & 0.096 \\
\hline Lowest & $83(30 \%)$ & $48(40 \%)$ & \\
\hline Middle & $102(37 \%)$ & $33(28 \%)$ & \\
\hline Highest & $90(33 \%)$ & $39(33 \%)$ & \\
\hline Total psoas tertiles & & & 0.052 \\
\hline Lowest & $83(30 \%)$ & $50(42 \%)$ & \\
\hline Middle & $99(36 \%)$ & $31(26 \%)$ & \\
\hline Highest & $92(34 \%)$ & $39(33 \%)$ & \\
\hline Average paraspinous tertiles & & & 0.826 \\
\hline Lowest & $78(32 \%)$ & $40(35 \%)$ & \\
\hline Middle & $81(33 \%)$ & $37(33 \%)$ & \\
\hline Highest & $83(34 \%)$ & $36(32 \%)$ & \\
\hline Total paraspinous tertiles & & & 0.791 \\
\hline Lowest & $76(32 \%)$ & $39(36 \%)$ & \\
\hline Middle & $82(35 \%)$ & $36(33 \%)$ & \\
\hline Highest & $79(33 \%)$ & $34(31 \%)$ & \\
\hline Female patients & 133 & 70 & \\
\hline Average L-4 psoas area† & $9.58 \pm 2.40$ & $9.82 \pm 2.88$ & 0.512 \\
\hline Total L-4 psoas area† & $19.15 \pm 4.80$ & $19.65 \pm 5.75$ & 0.512 \\
\hline Average T-12 paraspinous area† & $14.47 \pm 4.40$ & $14.99 \pm 4.85$ & 0.458 \\
\hline Total T-12 paraspinous area† & $28.48 \pm 7.55$ & $29.91 \pm 9.83$ & 0.315 \\
\hline Average psoas tertiles & & & 0.673 \\
\hline Lowest & $43(32 \%)$ & $24(34 \%)$ & \\
\hline Middle & $48(36 \%)$ & $21(30 \%)$ & \\
\hline Highest & $42(32 \%)$ & $25(36 \%)$ & \\
\hline Total psoas tertiles & & & 0.673 \\
\hline Lowest & $43(32 \%)$ & $24(34 \%)$ & \\
\hline Middle & $48(36 \%)$ & $21(30 \%)$ & \\
\hline Highest & $42(32 \%)$ & $25(36 \%)$ & \\
\hline Average paraspinous tertiles & & & 0.848 \\
\hline Lowest & $40(33 \%)$ & $23(35 \%)$ & \\
\hline Middle & $42(34 \%)$ & $20(30 \%)$ & \\
\hline Highest & $40(33 \%)$ & $23(35 \%)$ & \\
\hline Total paraspinous tertiles & & & 0.821 \\
\hline Lowest & $39(33 \%)$ & $22(34 \%)$ & \\
\hline Middle & $43(36 \%)$ & $20(31 \%)$ & \\
\hline Highest & $38(32 \%)$ & $22(34 \%)$ & \\
\hline Male patients & 142 & 50 & \\
\hline Average L-4 psoas area† & $15.43 \pm 4.32$ & $13.71 \pm 3.73$ & 0.014 \\
\hline Total L-4 psoas area† & $30.86 \pm 8.68$ & $27.43 \pm 7.45$ & 0.014 \\
\hline Average T-12 paraspinous area† & $19.35 \pm 6.85$ & $18.14 \pm 4.47$ & 0.183 \\
\hline Total T-12 paraspinous area† & $38.68 \pm 13.76$ & $36.09 \pm 8.84$ & 0.159 \\
\hline Average psoas tertiles & & & 0.032 \\
\hline Lowest & $40(28 \%)$ & $24(48 \%)$ & \\
\hline Middle & $54(38 \%)$ & $12(24 \%)$ & \\
\hline Highest & $48(34 \%)$ & $14(28 \%)$ & \\
\hline
\end{tabular}


TABLE 5. Morphometric comparisons of patients with and without complications (continued)

\begin{tabular}{cccc}
\hline Variable \& Response & No Complications & Complications & p Value* \\
\hline Male patients (continued) & 275 & 120 & 0.008 \\
\hline Total psoas tertiles & & & \\
\hline Lowest & $40(28 \%)$ & $10(20 \%)$ & 0.602 \\
\hline Middle & $51(36 \%)$ & $14(28 \%)$ & \\
\hline Highest & $50(35 \%)$ & & 0.573 \\
\hline Average paraspinous tertiles & & $17(36 \%)$ & $17(36 \%)$ \\
\hline Lowest & $38(32 \%)$ & $13(28 \%)$ & \\
\hline Middle & $39(33 \%)$ & $17(38 \%)$ & $16(36 \%)$ \\
\hline Highest & $43(36 \%)$ & $12(27 \%)$ & \\
\hline Total paraspinous tertiles & & & \\
\hline Lowest & $37(32 \%)$ & & \\
\hline Middle & $39(33 \%)$ & & \\
\hline Highest & $41(35 \%)$ & & \\
\hline * Boldface indicates statistical significance. & & & \\
\hline Values are presented as the mean \pm SD. & & & \\
\hline
\end{tabular}

For all patients, small total psoas tertiles approached significance for being associated with postoperative morbidity $(\mathrm{p}=0.052)$. These results were significant with multivariate regression analysis, with the lowest psoas tertile having an odds ratio of 1.70 (95\% CI 1.04-2.79, $\mathrm{p}=0.035)$ for a postoperative complication for all patients. For male patients, a small total psoas size and being in the lowest psoas tertile were both significant predictors of postoperative morbidity $(\mathrm{p}=0.014$ and $\mathrm{p}=0.008$, respectively). For males, the multivariate regression analysis calculated an OR of 2.42 (95\% CI 1.17-5.01, p = 0.016). The paraspinal muscle groups did not provide any significant data for postoperative morbidity, even after multivariate analysis. It is important to note that for males, the only variable in the multivariate analysis that was associated with higher risk of complication was being in the lowest psoas tertile.

\section{Interpretation}

This is the first time that morphometric analysis has been validated in spinal surgery, illustrating that psoas size may be used as a sensitive preoperative risk factor for perioperative morbidity in patients undergoing lumbar spine surgery. Morphometric analysis of psoas size was more sensitive than analyses of other preoperative risk factors (age, diabetes, smoking, CAD, and BMI) in predict- ing postoperative morbidity. Psoas size is particularly accurate in predicting postoperative morbidity, with smaller psoas sizes having statistically significant increased odds of complications. This is in agreement with the work of authors in other surgical disciplines. ${ }^{3,7,12,13,17,18,22,24}$ The association with preoperative psoas size and postoperative morbidity is especially apparent in male patients. It is important to note that our morphometric analysis was not predictive or statistically significant in female patients. There are two reasons for this. First, women have statistically significant smaller psoas muscles than males (Table 2 ). If the proposed model of sarcopenia and frailty is correct, female sex could represent an indirect risk factor for complications. Indeed, we did observe that women trended toward having an increased rate of complications compared with males (Table $4, p=0.068$ ). Second, the psoas muscle may not be the best choice to measure sarcopenia and frailty in women. This is evidenced by the fact that the size of the paraspinal muscles, which have an antagonistic action to the psoas muscles, was not predictive of postoperative morbidity in any situation. This suggests that not all muscle groups may be accurate when used for morphometric analysis and that there may be a better, more sensitive muscle group yet to be identified.

It is not surprising that age is associated with increased

TABLE 6. Multivariate results using lowest total psoas tertile vs other two tertiles*

\begin{tabular}{|c|c|c|c|c|c|c|}
\hline \multirow[b]{2}{*}{ Variable } & \multicolumn{2}{|c|}{ All Patients } & \multicolumn{2}{|c|}{ Males Only } & \multicolumn{2}{|c|}{ Female Only } \\
\hline & OR $(95 \% \mathrm{Cl})$ & $p$ Value & OR $(95 \% \mathrm{Cl})$ & $p$ Value & OR $(95 \% \mathrm{Cl})$ & $p$ Value \\
\hline Female sex & $1.46(0.93-2.28)$ & 0.103 & & & & \\
\hline Age (increase of 10) & $1.14(0.94-1.40)$ & 0.185 & $1.06(0.78-1.45)$ & 0.704 & $1.19(0.91-1.56)$ & 0.195 \\
\hline CAD & $1.34(0.73-2.48)$ & 0.346 & $1.65(0.75-3.64)$ & 0.214 & $0.96(0.36-2.59)$ & 0.940 \\
\hline Smoking & $0.65(0.38-1.12)$ & 0.118 & $0.75(0.35-1.61)$ & 0.465 & $0.55(0.25-1.21)$ & 0.138 \\
\hline BMI (increase of 5) & $1.22(1.02-1.46)$ & 0.030 & $0.99(0.72-1.36)$ & 0.942 & $1.32(1.05-1.66)$ & 0.016 \\
\hline $\begin{array}{l}\text { Total psoas (low vs middle \& high } \\
\text { tertiles) }\end{array}$ & $1.70(1.04-2.79)$ & 0.035 & $2.42(1.17-5.01)$ & 0.016 & $1.22(0.62-2.43)$ & 0.564 \\
\hline
\end{tabular}

* Boldface indicates statistical significance. 
risk for postoperative complications $(\mathrm{p}=0.015)$. Increasing age is a known risk factor for senescence and sarcopenia, which is indirectly being measured with our morphometric analysis. However, while age is sensitive for predicting sarcopenia, it is not specific, as there are persons of advanced age who have not lost muscle mass. ${ }^{9,21}$ It is noteworthy that diabetes, CAD, and BMI were not predictive of postoperative morbidity in all patients. Given that the majority of surgery performed in this study was elective in nature, these disease processes may have been under adequate control such that they did not impact the rate of postoperative complications; however, this might not be the case in the setting of an acute neurological deficit following an urgent or semielective operation. Our findings also underscore the relative imprecision of traditional methods for risk stratification in predicting postoperative morbidity. Our multivariate analysis shows that being in the lowest psoas tertile was more accurate at predicting postoperative morbidity than were age and all other premorbid states except for BMI in females. This suggests that morphometrics as a quantitative measure of sarcopenia and frailty may be more indicative of a patient's general health and their physiological reserve for tolerating surgery.

These findings are especially important in the current health care environment in the United States, as multiple parties (i.e., payers, the federal government, hospital administrators, and regulatory bodies) have begun to focus on the cost and value of care. As payments become bundled by procedure, and health care providers can potentially be penalized or withheld compensation for complications after routine procedures, it will be vital to identify predictors that put patients at a higher risk of morbidity. If a surgeon must perform a needed procedure in a potentially high-risk patient, a reliable model for risk stratification could provide some justification of perioperative morbidity. Regardless of the economic implications, a better understanding of the factors that will put a patient at increased risk of an adverse event after surgery is an important consideration for surgeons as they counsel patients and their families. Setting realistic expectations and providing accurate prognostic information is a key component in the delivery of care.

\section{Limitations}

The chief limitation of this study is its retrospective nature and relatively heterogeneous study population. Despite the robustness of our electronic medical record, we cannot account for potential bias and reporting error without standardization in data collection with each individual case. In addition, we considered all lumbar operations as a whole and did not stratify by indication (degenerative vs infection, tumor, trauma, etc.). Our findings highlight the need for future prospective multicenter trials.

\section{Conclusions}

Morphometric analysis of psoas size can be used as a sensitive tool to predict perioperative morbidity after lumbar spine surgery. Our results can be generalized to other institutions, as they were based on the experience of 12 surgeons across multiple hospitals, each with different practice patterns and techniques (i.e., minimally invasive surgery versus traditional open techniques).

\section{References}

1. Amrock LG, Deiner S: The implication of frailty on preoperative risk assessment. Curr Opin Anaesthesiol 27:330-335, 2014

2. Canvasser LD, Mazurek AA, Cron DC, Terjimanian MN, Chang ET, Lee CS, et al: Paraspinous muscle as a predictor of surgical outcome. J Surg Res 192:76-81, 2014

3. Deyo RA, Mirza SK, Martin BI, Kreuter W, Goodman DC, Jarvik JG: Trends, major medical complications, and charges associated with surgery for lumbar spinal stenosis in older adults. JAMA 303:1259-1265, 2010

4. Dodson RM, Firoozmand A, Hyder O, Tacher V, Cosgrove DP, Bhagat N, et al: Impact of sarcopenia on outcomes following intra-arterial therapy of hepatic malignancies. J Gastrointest Surg 17:2123-2132, 2013

5. Dunne MJ, Abah U, Scarci M: Frailty assessment in thoracic surgery. Interact Cardiovasc Thorac Surg 18:667-670, 2014

6. Englesbe MJ, Lee JS, He K, Fan L, Schaubel DE, Sheetz KH, et al: Analytic morphomics, core muscle size, and surgical outcomes. Ann Surg 256:255-261, 2012

7. Englesbe MJ, Patel SP, He K, Lynch RJ, Schaubel DE, Harbaugh C, et al: Sarcopenia and mortality after liver transplantation. J Am Coll Surg 211:271-278, 2010

8. Fleisher LA, Eagle KA: Clinical practice. Lowering cardiac risk in noncardiac surgery. N Engl J Med 345:1677-1682, 2001

9. Fried LP, Tangen CM, Walston J, Newman AB, Hirsch C, Gottdiener J, et al: Frailty in older adults: evidence for a phenotype. J Gerontol A Biol Sci Med Sci 56:M146-M156, 2001

10. García-Miguel FJ, Serrano-Aguilar PG, López-Bastida J: Preoperative assessment. Lancet 362:1749-1757, 2003

11. Goz V, Weinreb JH, McCarthy I, Schwab F, Lafage V, Errico TJ: Perioperative complications and mortality after spinal fusions: analysis of trends and risk factors. Spine (Phila Pa 1976) 38:1970-1976, 2013

12. Hasselager R, Gögenur I: Core muscle size assessed by perioperative abdominal CT scan is related to mortality, postoperative complications, and hospitalization after major abdominal surgery: a systematic review. Langenbecks Arch Surg 399:287-295, 2014

13. Lee JS, He K, Harbaugh CM, Schaubel DE, Sonnenday CJ, Wang SC, et al: Frailty, core muscle size, and mortality in patients undergoing open abdominal aortic aneurysm repair. J Vasc Surg 53:912-917, 2011

14. Makary MA, Segev DL, Pronovost PJ, Syin D, BandeenRoche K, Patel P, et al: Frailty as a predictor of surgical outcomes in older patients. J Am Coll Surg 210:901-908, 2010

15. Manchikanti L, Singh V, Datta S, Cohen SP, Hirsch JA: Comprehensive review of epidemiology, scope, and impact of spinal pain. Pain Physician 12:E35-E70, 2009

16. Oresanya LB, Lyons WL, Finlayson E: Preoperative assessment of the older patient: a narrative review. JAMA 311:2110-2120, 2014

17. Peng P, Hyder O, Firoozmand A, Kneuertz P, Schulick RD, Huang D, et al: Impact of sarcopenia on outcomes following resection of pancreatic adenocarcinoma. J Gastrointest Surg 16:1478-1486, 2012

18. Peng PD, van Vledder MG, Tsai S, de Jong MC, Makary M, $\mathrm{Ng}$ J, et al: Sarcopenia negatively impacts short-term outcomes in patients undergoing hepatic resection for colorectal liver metastasis. HPB (Oxford) 13:439-446, 2011

19. Rajaee SS, Kanim LE, Bae HW: National trends in revision spinal fusion in the USA: patient characteristics and complications. Bone Joint J 96-B:807-816, 2014 
20. Rubin DI: Epidemiology and risk factors for spine pain. Neurol Clin 25:353-371, 2007

21. Ruiz M, Cefalu C, Reske T: Frailty syndrome in geriatric medicine. Am J Med Sci 344:395-398, 2012

22. Sabel MS, Terjimanian M, Conlon AS, Griffith KA, Morris AM, Mulholland MW, et al: Analytic morphometric assessment of patients undergoing colectomy for colon cancer. $\mathbf{J}$ Surg Oncol 108:169-175, 2013

23. Scandrett KG, Zuckerbraun BS, Peitzman AB: Operative risk stratification in the older adult. Surg Clin North Am 95:149-172, 2015

24. Sheetz KH, Zhao L, Holcombe SA, Wang SC, Reddy RM, Lin J, et al: Decreased core muscle size is associated with worse patient survival following esophagectomy for cancer. Dis Esophagus 26:716-722, 2013

25. Shen Y, Silverstein JC, Roth S: In-hospital complications and mortality after elective spinal fusion surgery in the united states: a study of the nationwide inpatient sample from 2001 to 2005. J Neurosurg Anesthesiol 21:21-30, 2009

26. Smetana GW, Lawrence VA, Cornell JE: Preoperative pulmonary risk stratification for noncardiothoracic surgery: systematic review for the American College of Physicians. Ann Intern Med 144:581-595, 2006

27. Street JT, Lenehan BJ, DiPaola CP, Boyd MD, Kwon BK, Paquette SJ, et al: Morbidity and mortality of major adult spinal surgery. A prospective cohort analysis of 942 consecutive patients. Spine J 12:22-34, 2012

28. Taylor VM, Deyo RA, Cherkin DC, Kreuter W: Low back pain hospitalization. Recent United States trends and regional variations. Spine (Phila Pa 1976) 19:1207-1213, 1994

29. Trayner E Jr, Celli BR: Postoperative pulmonary complications. Med Clin North Am 85:1129-1139, 2001

30. van Meenen LC, van Meenen DM, de Rooij SE, ter Riet G: Risk prediction models for postoperative delirium: a systematic review and meta-analysis. J Am Geriatr Soc 62:23832390, 2014

31. Waits SA, Kim EK, Terjimanian MN, Tishberg LM, Har- baugh CM, Sheetz KH, et al: Morphometric age and mortality after liver transplant. JAMA Surg 149:335-340, 2014

32. Weinstein JN, Lurie JD, Tosteson TD, Hanscom B, Tosteson AN, Blood EA, et al: Surgical versus nonsurgical treatment for lumbar degenerative spondylolisthesis. N Engl J Med 356:2257-2270, 2007

33. Weinstein JN, Lurie JD, Tosteson TD, Skinner JS, Hanscom B, Tosteson AN, et al: Surgical vs nonoperative treatment for lumbar disk herniation: the Spine Patient Outcomes Research Trial (SPORT) observational cohort. JAMA 296:2451-2459, 2006

34. Weinstein JN, Tosteson TD, Lurie JD, Tosteson AN, Blood E, Hanscom B, et al: Surgical versus nonsurgical therapy for lumbar spinal stenosis. N Engl J Med 358:794-810, 2008

35. Yoshihara H, Yoneoka D: National trends in the surgical treatment for lumbar degenerative disc disease: United States, 2000 to 2009. Spine J 15:265-271, 2015

\section{Disclosure}

Dr. Chang reports being a consultant for Globus Medical.

\section{Author Contributions}

Conception and design: Zakaria, Chang, Griffith. Acquisition of data: Zakaria, Chang, Mossa-Basha, Griffith. Analysis and interpretation of data: Chang, Zakaria, Schultz, Griffith. Drafting the article: Zakaria, Chang, Schultz. Critically revising the article: Chang, Zakaria, Schultz, Griffith. Reviewed submitted version of manuscript: Chang, Zakaria, Schultz, Griffith. Approved the final version of the manuscript on behalf of all authors: Chang. Statistical analysis: Schultz. Study supervision: Chang.

\section{Correspondence}

Victor Chang, Henry Ford West Bloomfield Hospital, Department of Neurosurgery, 6777 W. Maple Blvd., West Bloomfield Township, MI 48322. email: vicchang@gmail.com. 